Journal Home Page:

http://perlinguam.journals.ac.za

\section{Per Linguam}

A Journal for Language Learning Tydskrif vir Taalaanleer

\title{
A CONTRASTIVE ANALYSIS OF LANGUAGE, CULTURE AND MEANING IN THE YORUBA AND ENGLISH LANGUAGES: A MODERN APPROACH AND A NEW PERSPECTIVE
}

\author{
Abdullahi-Idiagbon, M.S.(Ph.D) \\ English and Literature Department, Federal University Gusau, Nigeria
}

Some aspects of language use and cultural practices across the English and Yoruba languages are contrastively discussed. These include patterns and forms of greetings determined by spatiotemporal circumstances such as greetings and naming traditions, among other norms, to ascertain the aspects in which the two languages are alike and in which they differ. Illustrations are provided and differential descriptions offered through interlingual comparison. It was discovered that effective teaching and learning of a language will necessarily have to go beyond the boundary of symbols and language code to a fair knowledge of non-linguistic aspects of language. The paper concludes that learning a target language will be greatly enhanced and yield valuable results in terms of competence, proficiency, and most importantly, language pedagogy if the language and culture of the first and target languages are simultaneously studied.

Keywords: contrastive analysis, English, Yoruba, culture, language, pedagogy

\section{INTRODUCTION}

For decades, linguists have been carrying out a series of refreshing research on the relationship between language and culture because language is a veritable and indispensable instrument for cultural expression. Sapir and Whorf (1974:48-9), for instance, observe that 'the content of every culture is expressible in its language and there are no linguistic materials whether as to content or forms which are not felt to symbolize actual meaning'. This statement locates language within the spectrum of culture of its users. This is because, as corroborated by Pandey (2000), language is more of property of a society than being an index of status. Language, thus, reflects the society just as it is influenced by the same society it seeks to portray (Trudgil, 1974:24). It is therefore not coincidental but logical to state, that since language is a product of the environment, the meaning communicated by a particular language can only be derived from the same environment. This paper seeks to examine the synergy between language, culture and meaning in the English and Yoruba languages with a view to establishing points of divergence rather than convergence between the two in terms of how meaning is generated through culture.

The approach used in this study is not a traditional or classical one which compares and contrasts structures of a pair of languages to achieve only pedagogical gain. This research adopts a modern approach that considers language as a social action, a communicative tool whose focus is on function rather than form. This is in line with what James, (1980: 98) describes as a departure from micro to macro-linguistic issues which makes contrastive linguistics to be more concerned with discourse than structure. In addition, this contrastive analysis is from a sociolinguistic point of view because the tools for analysis are the major sociolinguistic variables. Focus is placed on specific areas where language use and meaning production reflect the English and Yoruba cultures. These areas include greetings, names of concepts, politeness phenomena, speech acts, rhetorical expressions and kinship terms. 


\section{LANGUAGE AND CULTURE}

Different approaches are used to study language, depending on the aspects that are considered attractive, significant and worthy of scholars' attention. The basic and perhaps universal impression of language is that it is a human activity through which ideas, feelings and desires are expressed in verbal and non-verbal forms. Non-verbal forms include signs, symbols, appearances, gestures and body language. As a concept, it is a veritable tool for socialisation through which we inform, instruct, teach, learn, entertain, express ideas and enter into elaborate relationships. It is a major facilitator of societal cohesion and the hallmark of people's life and culture. It mirrors people's worldviews, customs, ways of life and history in general, and through it, social reality is constructed. The language a people speak goes a long way in determining their cultural heritage and their perception of the external world.

Culture is a word that has been used in several ways outside the scope of anthropology, which is often conceived of as its primary constituency. Kluckolin and Kelly (1945:97) view culture as 'all those historically created designs of living, explicit and implicit, rational, irrational, which exist at any given time as potential guides for the behaviour of man'.

Anthropologically speaking, Oke (1998:2) defines culture as 'the knowledge, attitudes, and values people acquire as a result of belonging to a particular group'. Culture suggests a phenomenon developed, refined and domesticated by a society. It is the assemblage of socially inherited norms, beliefs and practices that determine the complexities of our lives (Barclay, 1986:17). From the submission of Barclay, it could then be inferred that culture is umbrella-like and encompasses a gamut of people's ways of life. It encompasses the beliefs, values, rituals and idea systems transmitted from the past and upheld by the present. Barclay (1986:17) sums up this notion of culture as the 'learned or acquired ideas - beliefs, knowledge, plans of action, rules and understanding that are available to people in a given society'.

Cultural elements include language, religion, greetings, belief, systems, superstitions, values, ethos, occupations, artefacts, music, myths and legends, etc. Some of these values are so deeply rooted in people's consciousness that they cannot easily be eroded though Western education and civilisation although social exposure and modern trends are now obviously taking their toll on many cultural values.

\section{THE SYNERGY BETWEEN LANGUAGE, CULTURE AND MEANING}

Language scholars and researchers agree that there is a close relationship between language and culture. Sapir and Whorf (1974:20) affirm the cultural content of a language as a behaviour determinant. Human behaviour could be explained in relation to the existence of social norms and values. In other words, social norms as reflected in language use have expression in social meaning (Cameron, 1997:60). Therefore, if language use reveals human social norms and practices (culture), any meaning derived from language use should take its cultural source as an intrinsic property of society. By implication, every culture subsumes language; thus, language is in culture and culture is in language. Larbalestier (2016) advises that, the teacher should be familiar with the language and culture of the learners in order to enhance the effective teaching and learning of the target language by constantly drawing major comparisons from the learners' first language, (L1).

Meanings are created within the cosmos of the interlocutors' experience or with recourse to the culture of a society. This explains why meanings cannot and should not be interpreted solely 
from linguistic expressions without adequately considering the cultural content of such expressions. Hymes (1997:12) argues for the need to study and describe the 'means of speech' and 'their meanings for those who use them'. After all, any language is an instrument at the disposal of its users. The nexus between language and culture is therefore symbiotic and complementary.

Language is bipolar: firstly, it is an abstract code, a system of expression that involves words and bodily postures. Secondly, it is an action, an identity marker of an individual or a society at large. The latter is neither written nor spoken; it is the way of life. However, both aspects have one thing in common - meaning. Even then, the universality of such meaning is not guaranteed. The former can generate a large amount of meaning which can be deciphered by applying semantic tools, with the exception of body language, whose meaning properties transcend semantics. The latter requires an absolute pragmatic apparatus -- most importantly, the context, in order to be communicative.

Linguistic elements and cultural practices are reciprocal and complementary in the production of a much more inclusive meaning in language. Both variables are indices of meaning by which mastery of language and effective teaching of the target language could be measured. This will enhance resourcefulness on the part of the teacher in creating and enhancing positive transfers at various levels of language study. A balanced bilingual teacher will take an advantage of his or her proficiency to drastically eliminate negative transfers on the part of the second language learners.

\section{CONTRASTIVE ANALYSIS: AN OVERVIEW}

Crystal (1992:83) defines 'contrastive analysis (as) the identification of points of structural similarity and difference between two languages' at linguistic levels such as phonology, grammar and semantics. According to Richard, Platt and Platt (1992:83), 'contrastive analysis was developed and practised in the 1950s and 1960s as the application of structural linguistics to language teaching'. Robert Lado (1957), who is considered a co-founder of modern contrastive linguistics, defines it as a means of identifying areas of difficulty for second language learners especially where learning is being impeded by the existing habit. The fundamental assumption is that errors made in the target language by learners are a result of interference from their L1. As such, they can be predicted and largely avoided with a good comparison between the mother tongue and the target language. Sapir and Whorf (1974) believe that language structure affects cognitive thinking. As a result, there is always a tendency to transfer of language rules from one language to another because second language learners tend to overgeneralise.

Although transfer of a rule or feature from one language to another is inevitable in the process of second language learning, not all the transfers that take place are acceptable in the target language due to the fact that transfer could be positive or negative. It is positive when the familiar skill facilitates the learning of a new structure in the second language. When the patterns are similar, i.e. when there is common ground, then the acquisition of such patterns is facilitated. However, it is considered negative when there are differences in the patterns because such differences can hinder the learning of a second or foreign language. Lado's (1957) assessment of the main difficulty of foreign language learning, based on the notion of transfer confirms that:

individuals tend to transfer the forms and in earnings in the distribution of forms and meaning of their native language and culture - both productively - and when attempting to speak the language and to act in the culture and receptively when 
attempting to grasp and understand the language and culture as practiced by natives. Those elements that are similar to this native language will be simple for him and those that are differences will be difficult.

\section{Approaches to contrastive analysis}

There are two major approaches in contrastive analysis: classical contrastive analysis and modern contrastive analysis (Abdi, 2010). The classical approach perceives language as a code and a system. Thus, the approach studies language system in relation to user competence, thereby approaching contrastive analysis from a linguistic competence point of view. In this approach, structural differences and similarities between two languages are studied. The structural areas include morphology syntax, phonology and vocabulary (lexis). Although this approach is tagged 'classical', it is still recognised and widely used by contemporary scholars and researchers.

Modern contrastive analysts have a social semiotic view of language. Language is conceived as a functional property of a society -- a communicative tool in social and cultural contexts -hence, language use must be pragmatic. The approach has moved contrastive analysis to the frontiers of functional linguistics. Hence, contrastive analysis is no longer confined to the study of formal or structural differences and similarities between two languages.

With this modern approach, contrastive analysis has extended its tentacles to such areas of functional linguistics as sociolinguistics, pragmatics, discourse analysis, translation, stylistics and semantics. In this approach, variables like cultural context and meaning as they relate to language are brought to bear in the process of analysis. Svalberg (2007) establishes the interconnectedness between language, culture and learning by assessing the impacts of language and culture on the learning of a target language. He infers that, if language is a social practice, then lexico-grammatical knowledge is not enough for language learners. He suggests an intercultural learning, which entails learning to understand cultural similarities and differences. Below is a simple diagram to illustrate the triadic symbiotic relationship between language, culture and meaning.

\section{Language}

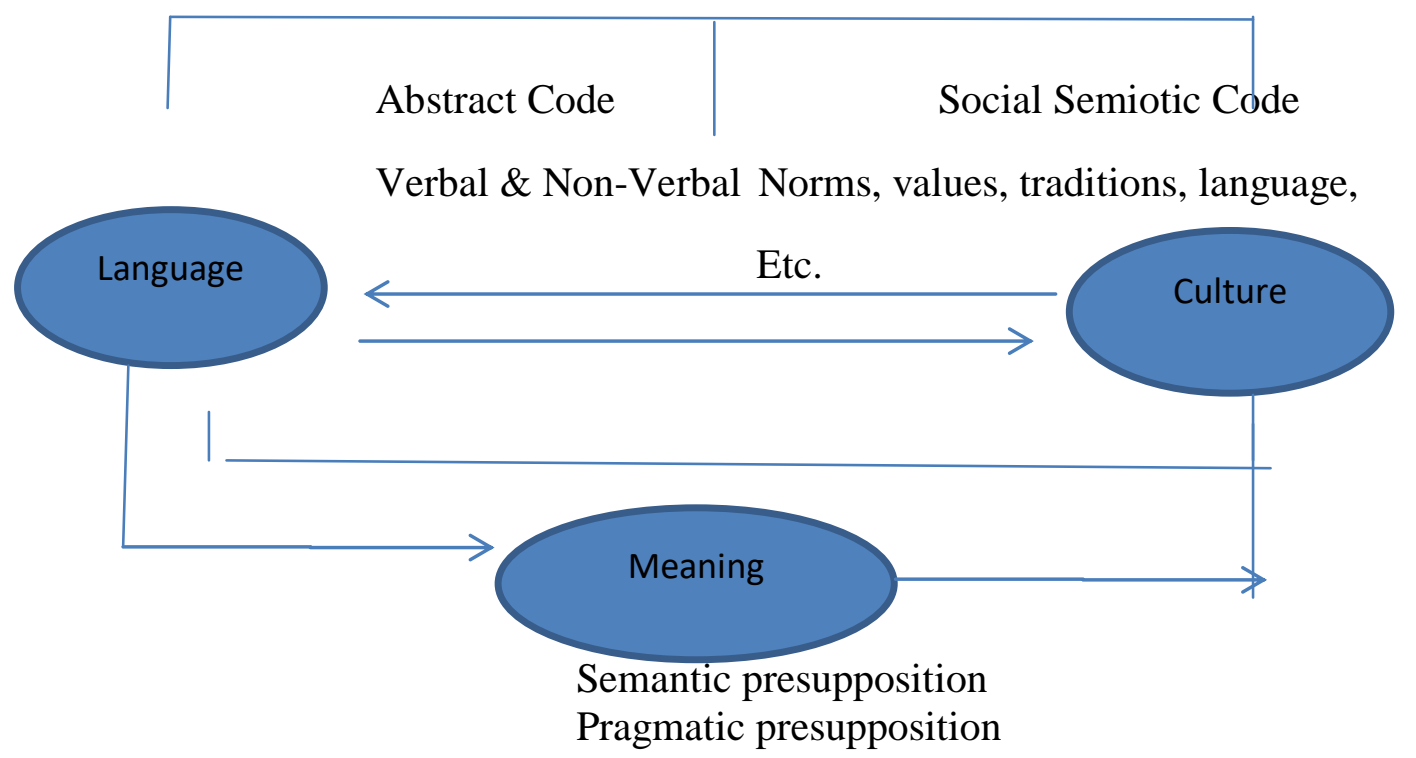

Figure.1: Language-culture-meaning network 
Haspelmath (2010:665) observes that contrastive analysis relies on 'comparative concepts' for crosslinguistic examination with a focus on the structure and meaning because these are adjudged to be universal phenomena in language study. Haspelmath (2010: 665) explains that comparison depends on the type of phenomenon being compared and suggests three ways of carrying out contrastive analysis, namely:

1. comparison based on form;

2. comparison based on generating function from form; and,

3. comparison across functional domains

The application of this corpus model is further discussed in the methodology section of this paper.

\section{A SYNCHRONIC OVERVIEW OF THE ENGLISH AND YORUBA LANGUAGES}

Today, the English language has grown to become not only an international language and a truly global language with the highest number of second language speakers but also a language that has come to forge unity among highly ethnically-biased speakers of African languages. Its sociolinguistic profile has risen to such an extent that it has left its native soil and established itself in numerous nations of the world, Nigeria included. Across the globe, today, the language is being put to several uses in several domains such as education, media, sports, law, creative and popular arts, business and commerce, science and technology, religion, politics and governance, and international and diplomatic relations.

It is pertinent to note here that the English language, as well as its cultural content, has always clashed with the cultures and languages of the societies where it functions either as a second language (L2) or a foreign Llnguage (FL). This situation has led to the emergence of varieties of the language in the world.

The Yoruba language, on the other hand, is a language spoken by the Yoruba people in the western part of Nigeria. It is perhaps the second most spoken indigenous language after the Hausa language. It is also spoken in Ajase community in the Republic of Benin, in Cuba, in Trinidad and Tobago, and, in Oyo town in the United States. It is one of over 400 hundred languages in Nigeria. Yoruba is also privileged to be one of the few languages that are officially recognised as 'major languages' in Nigeria. It has been codified, reduced to orthography and standardised. Hence, it is sometimes used among its speakers. in official domains such as education, media, religion and literary writings. It is allowed to be spoken in some linguistically homogenous state houses of assembly, especially in the southwestern part of the country.

\section{RATIONALE FOR THE STUDY}

It is axiomatic that Yoruba and English are historically unrelated language. While the English language originates from England, in Europe, the Yoruba language originates from southwestern Nigeria in Africa. This historical fact, notwithstanding, scholars have tried to carve out a common ground between the Yoruba and English languages as part of language universals. These points of convergence are:

- They are used by a considerable though not numerically similar number of bi- or multi cultural speakers either as the first or second language or lingua franca. 
- A substantial number of literary masterpieces (text, oral discourse) have been translated from these two languages into other languages. Consider, for example, the case of Ogboju Ode ninu Igbo Irunmale (Brave Hunters in The Forest of Spirits and Ogboju Ode ninu Igbo Olodunmare (Brave Hunters in The Forest of God).

In contemporary Nigeria, the English language coexists with Yoruba and other Nigerian indigenous languages as a result of its implantation and indispensability in Nigeria. Today, English has become the second language to numerous native speakers of Yoruba, who have come to learn English either as a school subject or a course of study at different levels of education, or as a medium of instruction in academic contexts. This is in addition to the fact that the language is used in several official domains, thereby, necessitating the acquisition of proficiency in English for both linguistic and communicative competence. With this situation, bilingualism between English and other Nigerian languages is passionately desired. In spite of its indispensability, many students increasingly fail English exams at various levels due to errors many of which are interlingual, and arise from wrongly equating the structure of English with the Yoruba mother tongue at lexical and semantic levels.

\section{METHODOLOGY}

Aijmer and Altenberg (1996:12) observe that using a multilingual corpus model can make issues conspicuous, that may be unnoticed in monolingual corpora, for exampl, exchange structure and systems, speech acts, and discourse functions. They opine that contrasting only the formal properties in languages, leads to an incomplete understanding of language. Comparison in terms of language specifics and universals as well as cultural and translation differences between the languages in focus also needs to be carried out.

Some elements were observed as determinants for effective learning of the target language in the course of the researcher's field experience, that is, while teaching English as a second language at various levels of learning at different times of his carrier. The selection was also a true reflection of scholars' opinions on the role of culture in aiding effective language learning as argued in the literature review section of this work.

British English is isolated because of the historical attachment of Great Britain to the English language. Of course, the concept of Englishes recognises regional varieties of English but the British and American varieties are the most popular. Since British English is the officially recognised variety in Nigeria, the researcher considered it preferable to use the British model in this paper as a basis for comparison with the Yoruba indigenous Nigerian Yoruba language.

The study adapts Haspelmath's corpus model with a slight modification. His first suggested step comparison based on form is not given prominence because, as earlier stated, this study is a new dimension to contrastive analysis. However, the illustrations, in this paper, show how form could generate specifics and universals in the two languages where domains and traditions differ as featured in the second step of the model. The focus is on linguistic lexes and expressions that are functional and culture-bound. The third step focuses on cross-linguistic comparison between the two languages in focus in order to show that different forms of expression, in most cases, are used in each of these two languages in the same context. However, in some instances of sharp differences in the culture and tradition of the two languages, a form of expression in one language may not be available in the other, and in that case, alternative functional utterances or expressions available in the English language are provided as discussed later in this paper. 
Findings from this study will help disentangle L2 learning difficulties. As earlier stated, the interest of the present study is not structural; rather, the study adopts the modern approach by investigating areas of difference between the English and Yoruba languages in relation to the interplay of language, culture and meaning. Difficulties are identified in words and other expressions whose meanings are Yoruba culture-bound; thus, presenting potential problems for an L2 English learner. It is the belief of the researcher that, if we can understand meaning through its cultural context, this can be used to anchor a new knowledge in the study of the target language.

\section{ASPECTS OF LANGUAGE, CULTURE AND MEANING IN THE ENGLISH AND YORUBA LANGUAGES: A CONTRASTIVE ANALYSIS}

The section explains how disparity in terms of language, culture and meaning impacts on the English and Yoruba communicative process. To achieve this, some areas of verbal interaction are considered which include greetings, prayers, politeness phenomena, kinship terms, names of concepts (food, other names, etc.) proverbs and speech acts. A detailed analysis of each of these is done in turn. The analysis contributes to the existing literature on L2 learning by sensitising learners to the fact that expressions and utterances in two languages do not necessarily correspond on one-to-one basis. Cultural values, norms and traditions shape what we say and how we say it. Yoruba learners of English are likely to have difficulty in composing or translating certain expressions into the English language due to the non-availability of such practices in Yoruba. Below, some elements analysed to illustrate the foregoing arguments.

\section{Greetings}

One area where cultural diversities could greatly affect the semantics of English and Yoruba is the area of greetings. It is a cultural value highly cherished among the Yoruba people. For every action, inaction, situation and event, there is a particular form of greeting usually preceded or prefixed by the morpheme $e k u$. The prefix $e k u$ precedes most greetings in Yoruba language, and it corresponds to 'good' in English. Hence, eku aaro means 'good morning'. However, when some Yoruba greetings that include $e k u$ are translated into English, the translation is rendered meaningless. So, overgeneralisation in the application of this prefix can cause difficulty in communication because it is a negative transfer. For instance, it is unconventional to interpret eku ikale (used in Yoruba culture to greet a person or a group of persons leisurely sitting or not.) or $e k u$ ijoko (a kind of greeting in Yoruba culture for somebody or a group of persons sitting leisurely alone or at a public event) as 'good sitting'. Similarly, eku ile (the form of greeting by a person returning home to those he or she meets at home) can be interpreted as 'good home' but this expression is non-existent in the English culture. English natives instead simply use 'hi', or 'hello'. While eku-abo, which is a response to such greeting means 'good return' in direct translation, the closest English expression is 'welcome back'. There are also different forms of ritualised greetings addressed to people involved in various cultural or non-cultural activities such as weddings, naming, festivals and building foundation-laying and other various cultural practices and ceremonies. Such greetings, as found in the Yoruba culture and manifested in the Yorba language, are not present in the English culture. Most, if not all, of these forms of greetings are covered by the expressions 'good day' and 'congratulations' in the English culture.

Similarly, the forms of greetings for different periods of the day vary. While the British culture recognises midnight (00:00) as marking the beginning of the day, the Yoruba concept of the 
morning begins when a Yoruba person wakes up at dawn. Hence, from about 05:00 to 06:30 the popular form of greeting is eku idaji. Between 7:00 and 9:00, it is ekaaro while by 11:55am when the concept of morning is still recognised in the British tradition, the concept of morning is over in Yoruba tradition., and the form of greetings then is eku iyaleta or eku ojo kanri a greeting that signals or acknowledges close 'movement' of the sun to its peak. The differences in the British and Yoruba expression of the phases of time as shown above define their semantic concept of time.

Yoruba culture accords great respect to expression of appreciation. Two proverbs in Yoruba attest to this claim:

- Eni ti a se loore ti ko dupe, bi olosa keru eni lo ni (an unappreciated gesture is as painful as a loss of valuables to hardened robbers).

- Bi omode ba dupe ore ana, yoo gba omiran (a child who expresses appreciation of a previous day's gesture shall live to receive another [gesture]).

Various forms of gestures are instantly appreciated in expressions such as 'thanks', 'thanks a lot', 'many thanks' in the British culture. It is not customary for an English person to reappreciate the gesture of a previous day in form of greeting on the second day. Conversely, in the Yoruba culture, such a gesture: is appreciated and re-appreciated several times over several days:

E seun. (thank you)

E seun eekan. (thank you for the gesture you made the other time)

E seun ana. (thank you for the gesture you bestowed on me yesterday)

E seun ojo. (thank you for the gesture you bestowed on me the other day (i.e the day the gesture was made).

The types of expressions described above are also regarded as forms of greetings. This is because, in the Yoruba community, greetings have social functions like the expression of appreciation or felicitation, apology, sympathy and condolences as well as supplication. These functions can be said to be the 'speech acts' of greetings in the Yoruba language. So important are these forms of greetings in the Yoruba culture that any beneficiary who fails to appropriately observe these greetings is considered uncultured, ill-bred and ungrateful. In the British culture, however, such greetings are not only culturally inconsequential but also meaningless.

In the same vein, the form of greeting for a Yoruba woman who gave birth to a new baby is supremely expressive of the relatedness of cultural values and experiences to meaning expression. To say 'eku ewu' (you are congratulated on surviving the danger of childbirth), as it is expressed to such a woman, is to rejoice with her for having successfully overcome or survived the throes of childbirth. In the ancient Yoruba communities where maternity wards were non-existent, the violent pain especially at the moment of childbirth was considered dangerous and excruciating. A woman who survives the agony of such moments is culturally conceived to have successfully trudged the terrain of danger, hence the greeting 'eku ewu'. In the Western world, on the contrary, scientific pre-natal care, terminating at the point of childbirth, has been in existence for a long period of history. Therefore, the expectant mother does not experience many throes as she is 'delivered of the baby'. To the woman who is 'assisted' in bringing forth the baby, 'congratulations' is an expression of greeting. 
An organiser or a celebrant also receives a special ritualised form of greeting from friends, neighbours, well-wishers and participants alike. To such an organiser, the greetings 'eku inawo 'eku inawo ana' and 'eku inawo ojo' (Congratulations on the event of yesterday! Congratulations on that particular day or event respectively!), are lavishly addressed on the day, second day and days after the event. These greetings are designed to acknowledge or praise the perceived large amount of money that the organiser spent on the event. Again, the British culture does not recognise this seemingly unending greeting!

The foregoing forms of greetings in the Yoruba culture are reflected in the Yoruba language and are meaningful among Yoruba speakers. However, such greetings are alien to and absent from the British culture and language. This cultural disparity, no doubt, tends to present difficulty for Yoruba individuals speaking or learning English as a second or foreign language. Learners of English as an L2 necessarily need to grapple with this difference in order to avoid deviant expressions emanating from the cultural interference of the mother tongue. At the same time, the knowledge of this tradition will make the teacher guide the learners to use appropriate words and expressions that correspond to the intended meaning of the learners.

\section{Names and meanings of concepts}

Another area where the influence of culture and meaning creates a difference between the English and Yoruba languages is in the area of names of concepts. The British culture recognises the concept 'Satan' as an invisible evil power and God's opponent. Such a concept does not exist in the Yoruba culture (mythology). On the contrary, Yoruba mythology recognises 'Esu', as a deity, believed to be the source of all unfortunate events. He is never believed to be God's opponent but rather His messenger on earth. It was therefore an error on the part of Bishop Samuel Ajayi Crowder to have equated the English 'Satan' to the Yoruba 'Esu' in his translated Bible. 'Satan' and 'Esu' are two different concepts in these two cultures; hence, they should reflect two different meanings.

Food is a component of culture. Meals are therefore given different names in different cultures. Food items may be common to two cultures but meals made from various foodstuffs vary across cultures as do the names they are called. For instance, 'beans' is common to both English and Yoruba cultures but the meals made from beans differ. In the Yoruba culture, moinmoin, ekuru, akara, alapa and adalu, for example, are made from beans. Such meals are not found in the English culture, hence, there is no English lexicon for them. This is another source of learningdifficulty for a Yoruba-English bilingual.

Colour is another serious issue. While the Yoruba culture recognises only three shades of colour, namely, $d u d u$, pupa and funfun- the English culture recognises quite a number of colour shades. Each of the three colour shades found in Yoruba has several shades in the English culture. This situation puts a Yoruba individual learning English in a tight corner with regard to how to express his or her colour experiences in English. To cope with challenges arising from colour identification, Yoruba people have coined words like resuresu, alawo eeru (ash colour), alawo ewe (green), kalakini (dotted pattern colour), baba, ayinrin, to describe corresponding colours in English. What learners need to understand is that, in most cases, they will need to resort to compound words or phrases in order to capture some of these Yoruba colours. For instance, kalakini means a particular main colour with other dotted-spot colours. 


\section{Politeness Culture}

Politeness phenomena, which are highly cherished among the Yoruba, present a fascinating disparity between the Yoruba and English languages. Yoruba culture accords great respect to age parity and position. As a mark of respect, certain plural pronouns in the Yoruba language are specifically used to address the elderly and individuals who tower above others on the social ladder. So awon (they), won (them/their) and eyin (you - plural) are honorifics plural pronouns used in addressing or referring to fathers by their children, teachers by their pupils, rulers by their subjects and even husbands by their wives. On the contrary, the respect, which the English culture accords the categories of people mentioned above, does not extend to the use of honorifics.

Again, this cultural difference may impact negatively on the use or learning of English pronoun markers by a Yoruba individual. This is manifest in the expression 'they are coming' when the person being referred to by 'they' is the speaker's boss in the office, for instance. Any Yoruba individual that uses the singular pronoun o that is (he/she) in the Yoruba cultural setting to refer to an elder or his or her boss is seen as being rude, arrogant or uncultured. Using they (an equivalent of the Yoruba awon) to refer to a single individual is not recognised in the English culture and is simply considered as a grammatical error in the use of language.

To avoid interlanguage or direct-translation in language, which is a syndrome of language incompetence, it is necessary to understand the similarities and differences in how pronouns are used in the two languages. This will guide the applied language teacher to teach English to Yoruba learners more effectively.

\section{Kinship Terms}

Kinship terms in the Yoruba culture convey meanings markedly different from those available in the English culture. These include family members like baba (father), momo (mother), iyawo (wife), egbon (elder brother) and aburo (younger brother). Meanings of these words in the Yoruba culture extend far beyond the scope of the British kinship. In the English culture, 'father' is usedto refer to one's biological male parent:;'mother', one's biological female parent; 'brother, one's younger or older male sibling; 'sister', one's younger or older female sibling; 'uncle' one's father's or mother's brother; 'aunt', one's father's or mother's sister, 'cousin', one's uncle's or aunt's male or female child, and 'nephew' and 'niece', one's brother's or sister's male and female child respectively.

In contrast, the Yoruba baba (father) is used to refer to one's biological male parent as well as one's paternal and material uncles. The same thing applies to mama (mother). iyawo (wife) in the Yoruba culture is used to refer to one's female spouse as well as the female spouse of one's brother, uncle, male cousin and or child. In the same vein, oko (husband) is used to refer to a woman's spouse as well as her spouse's male cousins, brothers and nephews. By virtue of the semantic extension of these terms, a Yoruba wife belonging to only one man is referred to as iyawo mi (my wife) by all members of the family, and the wife refers to certain male members of the family as oko mi (my husband). This complex semantic disparity between the English and Yoruba kinship terms is yet another source of difficulty for Yoruba L2 learners of English. As illustrated, these forms of address could seriously impair second language learning. So, the difference in notional meaning should be noted and should guide the learners in the appropriate choice of words for the intended meaning. 


\section{Stylistic and rhetorical expressions}

There is hardly any culture that does not use stylistic expressions to flavour speech. Stylistic expressions, as found in proverbs, idioms, metaphors, axioms, etc.., are rooted in the philosophy or worldview of a society. Besides, the cultural contents of such usages have a great impact on the meanings they convey; therefore, understanding such expressions requires being familiar with their cultural milieu.

The Yoruba proverb, Alaaru to nje buredi awo ori ara re lo nje (an alaaru who eats bread also eats from the skin of his head), makes sense only in the Yoruba culture. The word Alaaru is used to refer to a person whose livelihood is obtained by transporting goods for people, usually by carrying such goods on the head or by pushing it with a truck. The practice of carrying other people's goods for a fee and for a livelihood is quite alien to the western world. Thus, it will be very hard for a Yoruba speaker or learner of English to find a word that can express the concept of alarua., since this is not available in the British culture. This leaves the learners to search for proverbs that can closely convey related ideas or meaning. Let us consider the following proverb:

Eni ti a fun l'obi ti o dupe, ti a ba fun l'omo koni dana (a person who is offered kola nuts but fails to appreciate the offer, such a man would definitely not show appreciation if offered a daughter in marriage).

This saying takes its meaning from its cultural context. In the Yoruba culture, a kola nut has a huge cultural value. The Yoruba people attach much spiritual importance to it because it is an item used in traditional festivals and social events like naming, ceremonies, traditional 'graduation' ceremonies, housewarming and marriage. By virtue of its cultural importance, the best way to demonstrate love and hospitality is to offer kola nuts to a guest who, in return, appreciates this gesture. Similarly, the Yoruba culture accords a great sense of generosity to the act of giving out one's daughter in marriage. In fact, two intimate fathers, sometimes, facilitate a marriage between their children to cement their friendship. To appreciate this kind of gesture, the Yoruba culture requires the beneficiary (son-in-law) to pay specific amount of money and items. Failure to do so puts a social stigma on such an in-law. The analogical proverb cited above rhetorically warns against bestowing a gesture on somebody who is ungrateful. The point being made here is that the intended meaning of the axiom can be comprehended by unravelling its cultural content. However, the cultural practice is strange to the English culture; a practice similar to this is the offer of flowers to show love or respect, or to immortalise a beloved deceased. This situation can impede effective learning or speaking of English by Yoruba learners of English. No doubt, the English gloss provided for the axiom above cannot convey its semantic import in a context in which English functions L1 or mother tongue.

\section{Speech acts}

The much-quoted speech act theory of Austin (1962), holds the view that linguistic expressions are used to perform actions. Austin proposes direct and indirect speech acts. A direct speech act, according to him, exists when there is a match between the structural or semantic proposition of an utterance and the intended illocutionary force of that utterance. Conversely, an indirect speech act is when there is no direct match between the structural proposition of an utterance and the illocutionary act the speaker uses it to perform. Although the English and Yoruba languages are similar in the areas of performatives and constatives, they exhibit differences in terms of the illocutionary and perlocutionary acts of utterances. 
Again, cultural value is brought to bear here. In the British culture, polite requests are, more often than not, made with questions instead of imperative utterances. Hence, 'Can you pass the salt?' and 'Can you turn off the radio?' are likely to be requests rather than commands. In the Yoruba culture, questions are presented as questions, requests as requests and imperatives as imperatives. The Yoruba equivalents of the above statements, 'Nje o le fun mi ni iyo yen? (Can you pass the salt?) and 'Nje o le pa radio yen?' (Can you turn off the radio?) will be interpreted as questions and will elicit answers such as 'rara' (no) or 'beeni' (yes) instead of eliciting actions on the part of the addressee, as intended by the speaker. This is because they are questions than requests.

It was reported that in a secondary school, in the Yoruba land, a whole assembly of students responded 'No' when a teacher conducting an assembly, after a prolonged speech, said, 'Shall we sing the national anthem?' Apparently, the students were bored by the teacher's long speech, so, they responded 'No' because they thought the teacher was asking whether they should still sing the national anthem whereas the utterance was a request cum polite order. Such a misinterpretation would not have occurred if the teacher had used an imperative structure like 'Let us sing the national anthem' which is a traditional, direct speech act in the pragmatics of the Yoruba language. Such an erroneous meaning retrieval cannot occur in the British culture.

In the Yoruba culture, 'Can you pass the salt?' and 'Can you turn down the radio?' will simply be rendered as 'fun mi ni iyo." (pass the salt) and 'jowo) pa radio yen.' (please) turn off that radio). Therefore, the speech acts system in the cultural context of the utterance would have its meaning coded in consonance with the speech act system in the cultural context of the utterance. This is another point of divergence between the English and Yoruba languages.

\section{FINDINGS AND IMPLICATIONS}

This study has probed into the essential areas where culture and meaning show differences between the English and Yoruba languages. This contrastive study has revealed that some differences in the contrasted languages stem from the differences in the cultural ways in which the native speakers of the two languages communicate meanings in their respective sociocultural contexts. These contrasts have implications for such domains as language pedagogy, Nigerian English, lexicography, translation and language teaching materials.

In language pedagogy, the study is significant in terms of English language teaching and learning where the learners are Yoruba speakers. The teacher requires adequate familiarity with areas of difference in order to predict errors ensuing from these differences. The learner equally needs to be abreast of these contrasts so that he or she can be conscious of the tendency to transfer meaning and culture, from the mother tongue, Yoruba into the target language, English. Also, the teacher should be conscious of the fact that teaching structural features of English is not sufficient to achieve effective teaching and learning in the L2 situation.

For Nigerian English, this study has many implications. As pointed out earlier, the English language is in a 'forced exile' in Nigeria. Thus, the language coexists with Yoruba and even assumes a more desirable sociolinguistic status than Yoruba, thereby, forcing Yoruba native speakers to use English as their L2. This situation has naturally compelled the adaptation of English to the Yoruba culture in order to suit the Yoruba-English bilinguals' communicative needs. Consequently, a regional variety of Nigerian English known as 'Yoruba English' emerged. This sociolinguistic approach to contrastive study therefore offers an explanation on 
why such a variety of English has emerged, namely, the inevitable transfer of the Yoruba culture and language into English. This corroborates Lado's (1957) position that L2 learners tend to transfer culture and meaning from their L1 into their L2.

As for lexicography, this study has implications for the compilation of a bilingual dictionary involving English and Yoruba. Lexicographers will benefit from the findings of this study so that lexical entries from English and Yoruba are not exposed to semantic misrepresentations. The bilingual lexicographer must necessarily be familiar with the pragmatics and sociolinguistics of both languages. Failure in this respect will defeat the utilitarian essence of the dictionary, as its users will be grossly misled by semantic misrepresentations of lexical entries.

Furthermore, there are implications for translation. Translation is a serious business involving converting a text (written or spoken) from one linguistic medium into another. Here, again, a contrastive study of this type has a role to play. Insights drawn from the differences between culture and meaning in English and Yoruba can be deployed in Yoruba English or English Yoruba translation exercises.

In the area of language curriculum design, adequate knowledge of the points of convergence as found in the culture and meaning of the English and Yoruba languages will help a great deal in designing an effective English language curriculum for learners who are Yoruba speakers. In this task, the designer requires familiarity with the linguistic and cultural background of the Yoruba learners of English vis-à-vis the target language and its culture. This will assist the designer in determining what to teach, and what to learn, at what stage of learning. Finally, the study has implications for applied linguistics, pragmatics, psycholinguistics, sociolinguistics, bilingualism and language education.

\section{SUMMARY AND CONCLUSION}

This paper undertook a contrastive study of the English and Yoruba languages by looking into how meaning is produced via culture in the two languages and how this affects lexical choice, lexical equivalents and translation. To establish a conceptual framework, the researcher reviewed the concept of language, culture and meaning on the one hand and contrastive analysis on the other. A cursory survey of the English and Yoruba languages was also made and the rationale for the study established.

Focal areas included greetings, names of concepts, politeness phenomena, kinship terms, stylistic expressions and speech acts. The study may be considered a sociolinguistic approach to contrastive study. This is in view of its focus on fundamental sociolinguistic variables such as language, culture and meaning as well as a host of social variables as discussed earlier. This departure from the classical approach of contrastive analysis of the structures of languages bestows on this study the status of a new dimension to contrastive analysis. The approach is a worthwhile one as it addresses the position of language as a socio-semiotic and communicative tool, rather than a system of arbitrary vocal sounds to be studied to achieve mere linguistic competence.

The study underscores dynamism and contextuality in language use in general and, learning, in particular. It rates communicative competence over linguistic competence because it has been observed that errors and mistakes in constructions are still rampant despite some learners' high scores in English syntax. Poor knowledge of the native speakers' culture, which consequently compels the L2 speakers to find alternative expressions in English, is perhaps, one of the reasons 
for the emergence of various local-breed English variants in the world, Nigeria included. All these factors have a catastrophic influence on the learning of English language skills. Thus, there is an increase in the number of failures in English examinations among students at various levels.

\section{REFERENCES}

ABDI, N. (2010). Contrastive Analysis and Error Analysis. (1-2).

AIJMER, K. \& B. ALTENBERG. 1996. Introduction. In K. Aijmer, B. Altenberg, \& (Eds.), Language in contrast. Papers from Symposium on Text-Based Studies, Lund, Sweden, March 1994, Lund, Sweden: Lund University Press. 10-16.

AUSTIN, J. 1962. How to do things with words. Cambridge: MA: Havard University Press.

BARCLAY, H. 1986. Culture the human way. Calgary, Alberta: Western Publishers.

CAMERON, D. 1997. Demythologizing sociolinguistics in N. Coupland, \& A Jaworski, (Eds). Sociolinguistics-a reader and course book. New York: Palgrave. 55-56

CRYSTAL, D. 1992. Linguistics. Harmonsworth: Penguin.

HASPELMATH, M. 2010. Comparative concepts and descriptive categories in cross linguistic studies. Language 86.(3): 663-687.

HYMES, D. 1997. The scope of sociolinguistics in N Coupland, N.\&A. Jaworski, (Eds). Sociolinguistics $-A$ reader and course book. New York: Palgrave. 12-23.

JAMES, C. 1980 Contrastive Analysis. London: Longman.

KLUCKOLIN, C. \& WH KELLY. 1945. The concept of culture in R. Linton. (Ed.). The Science of man in world crisis. New York: Columbia University Press.

LADO, R. 1957. Linguistics across cultures:applied linguistics for language teachers. Ann Arbor: University of Michigan Press.

LARBALESTIER, D. 2016. Learning a language through cultural immersion Available from http://www.insearch.edu.au/blog/studying-english/cultural-immersion. (Accessed:2 February, 2016)

OKE, N.O. 1998. The nature of language in I Emeka (Eds.) Language and communication: a text for tertiary institutions. Aba: Assemblies of Press.

RICHARD, JC., J PLATT, \& H PLATT. 1992. Dictionary of language teaching \& applied linguistics. Essex: Longman.

SAPIR, E. \& B. WHORF, 1974. Language in G. Blount, (Ed.) Language culture and society. Cambridge: Winthrop 32-49.

SVALBERG,L2007. Language awareness and language learning. Language Teaching. 40,: 287308 doi:10.1017/S0261444807004491. 12/02/2016.

TRUDGIL, P. 1974. Sociolinguistics: an Introduction to language and society.

Harmondsworth: Penguin Books.

\section{BIOGRAPHICAL NOTE}

Abdullahi-Idiagbon is a lecturer in the Department of English and Literature at the Federal University Gusau, Nigeria. He has published in local, national and international journals and attended conferences across the globe. His research interests are Discourse Analysis, Sociolinguistics, Applied Linguistics and Syntax.

Email: msidiagbon@gmail.com 